American Journal of Applied Sciences 7 (1): 71-76, 2010

ISSN 1546-9239

(C) 2010 Science Publications

\title{
Study of Seven-Lump Kinetic Model in the Fluid Catalytic Cracking Unit
}

\author{
Mehran Heydari, Habib AleEbrahim and Bahram Dabir \\ Department of Chemical Engineering, Amir Kabir University of Technology, \\ 424, Hafez Ave, Tehran, P.O. Box 15875-4413, Iran
}

\begin{abstract}
Problem statement: The effective simulation of the Fluid Catalytic Cracking (FCC) operation requires a good understanding of many factors such as, reaction kinetic, fluid dynamics and feed and catalyst effects. Approach: In this model the reactor has been considered as an isothermal riser. The reactions in the riser occur with the fluid and the solids in ideal plug flow. Because of complication of the catalytic cracking mechanism and existence of multi-components in the feed, to decrease the calculation content in the kinetic models, the reactants and products have been considered as a set of hydrocarbons, so these models are called "Lumped Models". Results: To simulate the FCC riser, the seven-lump model involved residual oil, heavy lump, light lump, liquefied petroleum gas, gasoline, dry gas and coke (to predict the feed conversion and the product distribution) has been developed. Conclusion: Simulation studies are performed to investigate the effect of changing various process variables, such as temperature and residence time. Comparison of simulation results with industrial ones shows that the simulation has been achieved accurately.
\end{abstract}

Key words: FCC, riser reactor, riser simulation, lump kinetic model, hydrodynamic model

\section{INTRODUCTION}

The Fluid Catalytic Cracking (FCCU) is the primary conversion unit in oil refinery operation. The Fluid Catalytic Cracking (FCC) unit is one of the most important processes in the petroleum refining industry. Heavy petroleum fractions are catalytically cracked to lower molecular weight products. In the FCCU riser, lift steam pushes the dense catalyst bed upward from the riser base to the feed injection point. The feed enters as liquid droplets along with atomizing steam, contact the hot catalyst and rapidly evaporates. As the suspension of catalyst powder in reactant gases rises upward, the gas is cracked to lighter hydrocarbons (gasoline and light gases) and coke. The coke is deposited on the catalyst, which is transported out of the riser and into the regenerator, where the coke is burned off the catalyst in a combustion environment. The hot regenerated catalyst is then reinjected into the base of the riser (Pugsley and Dalai, 2004). Because of generation of gas by the cracking reactions, the gas velocity increases from $4.5-6 \mathrm{~m} \mathrm{sec}^{-1}$ near the riser base to $15-20 \mathrm{~m} \mathrm{sec}^{-1}$ at the riser exit. New world trends in product demands to meet more severe legislation about fuel composition, raise the significance of controlling the FCC product selectivity. The complexity of gas oil mixtures, which are the typical FCC feeds, makes it extremely difficult to characterize and describe the inherent kinetics at a molecular level. In this way similar components are grouped into a few "cuts" or "lumps. Therefore, the study of the reactions involved in the catalytic cracking process has followed the lumping methodology. The number of lumps of the proposed models for catalytic cracking reactions has been consecutively increasing to obtain a more detailed prediction of product distribution (Bollas et al., 2007). In the first kinetic model (3-lump), proposed by Weekman (1968), reactants and products were lumped into three major groups: Gas oil, gasoline and light gas plus coke. Lee et al. (1988); Lee et al. (1989) took one step forward by dividing the light gas plus coke lump into two different lumps $\mathrm{C}_{1}-\mathrm{C}_{4}$ gas and coke, developing the first 4-lump models for fluid catalytic cracking. Advancing the lumping methodology, Corella and Frances (1991) developed a 5-lump models, in which the gas-oil lump was divided into its heavy and light fractions. Dupain et al. (2006) simplified the 5-lump model of Corella and Frances for the specific case of the catalytic cracking of aromatic gas oil, by reducing the reactions involved in the lumping scheme. Another 5-lump model was developed by Kraemer et al. (1991) in which the 3-lump model of Weekman was modified by splitting the gas oil lump into aromatic, paraffinic and naphthenic lumps. Ancheyta et al. (1999)

Corresponding Author: Mehran Heydari, Department of Chemical Engineering, Amir Kabir University of Technology, 424, Hafez Ave, Tehran, P.O. Box 15875-4413, Iran Tel: +989121752593 
followed a different approach in their 5-lump models development, in which they considered the gas oil as one lump, but divided the gas lump into two lumps (liquefied product gas and dry gas). Oliveira and Biscaia (1989) (emphasizing in the catalytic cracking of gasoline and paraffinic gas oils). Hagelberg et al. (2002) expanded the 5-lump model of Ancheyta-Juarez et al. (1999) to an 8-lump model by dividing the gasoline fraction into paraffins, olefins, naphthenes and aromatics. The more advanced model was proposed by Jacob et al. (1976) which included 10 lumps (light and heavy gas oil paraffinic, naphthenic and aromatic rings and substituent). On the basis of the 10-lump model of Jacob et al. (1976); Ellis et al. (1998) developed a more advanced model capable of predicting the light gas product slate, using empirical algebraic equations. With presence of the high efficiency feed injection system in modern FCC units cause all cracking in the riser occur during the short time about 1-5 sec (Arandes and de Lasa, 1992; Arbel et al., 1995; Han and Chung, 2001; Ali and Rohani, 1997), so in the present research, a one-dimensional isothermal for the FCC unit riser has been developed that combines a predicative riser hydrodynamic model with a seven-lump kinetic model. The model has been validated by comparison with industrial FCC unit riser conversion and yield data available from literature (Mu et al., 2003).

Mathematical modeling: The model is based on the schematic flow diagram presented in Fig. 1. The upper fluidized bed immediately above the riser acts as a disengaging chamber where vapor products and heavy components are separated from the catalyst using stripping steam. The only effect of the stripping process is to remove hydrocarbon gases adsorbed inside the pellets before the spent catalyst is sent to the regenerator. Fresh gas oil is brought into contact with the hot regenerated catalyst at the entrance of the riser which leads to the vaporization of gas oil. The inlet zone is considered to be the most complex part of the riser. This is attributed to the presence of high turbulence, high temperature and concentration gradients and flow inhomogeneity. To maintain a good balance between kinetics and applicability of the model, it has been considered a model with seven lumps for predicting the behavior of the unit. The model is divided into VR (vacuum.residue, $>500^{\circ} \mathrm{C}$ ) and VGO (vacuum gas oil, $350 \sim 500^{\circ} \mathrm{C}$ ), HFO (heavy fueloil, $350 \sim 500^{\circ} \mathrm{C}$ ), LFO (light fuel oil, $200 \sim 350^{\circ} \mathrm{C}$ ), G (gasoline, $\mathrm{C}_{5} \sim 200^{\circ} \mathrm{C}$ ), $\mathrm{S}_{1}$ (liquefied petroleum gas, $\mathrm{C} 3 \sim \mathrm{C} 4), \mathrm{S}_{2}$ (dry gas $\mathrm{C} 1 \sim \mathrm{C} 2$ ) and $\mathrm{C}$ (coke) according to their distillation ranges (Xu et al., 2006).

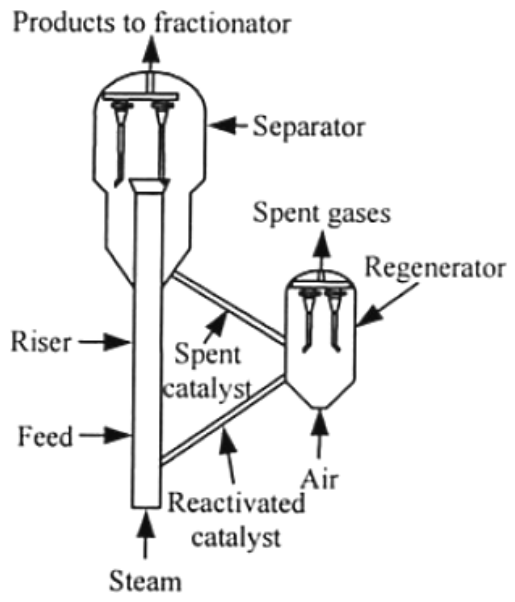

Fig. 1: Schematic diagram of catalytic cracking unit

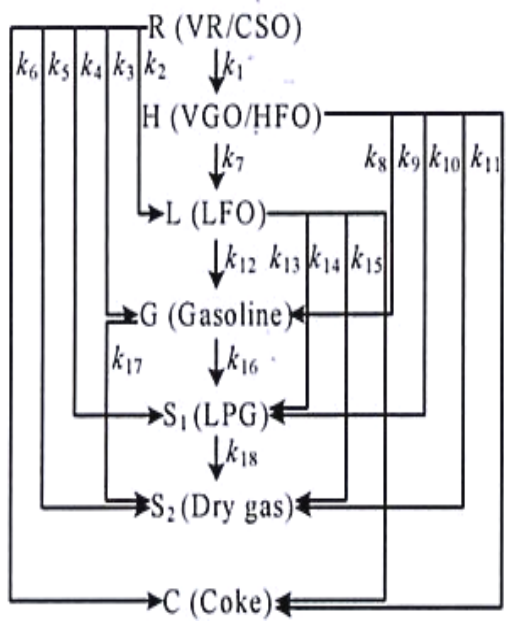

Fig. 2: Seven-lump reaction scheme for catalytic cracking unit

Figure 2 shows the reaction scheme diagram for catalytic cracking unit. The reactions involved in the reaction network are described by Eq. 1-7:

$$
\begin{aligned}
& \frac{\mathrm{dy}_{1}}{\mathrm{dx}}=\varnothing\left(\mathrm{t}_{\mathrm{c}}\right) \mathrm{f}\left(\mathrm{C}_{\text {Arh }}\right) \mathrm{cte}\left[-\left(\mathrm{k}_{1}+\mathrm{k}_{2}+\mathrm{k}_{3}+\mathrm{k}_{4}+\mathrm{k}_{5}+\mathrm{k}_{6}\right)\right] \mathrm{y}_{1} \\
& \frac{\mathrm{dy}_{2}}{\mathrm{dx}}=\varnothing\left(\mathrm{t}_{\mathrm{c}}\right) \mathrm{f}\left(\mathrm{C}_{\mathrm{Arh}}\right) \operatorname{cte}\left[\left(\mathrm{v}_{\mathrm{rh}} \mathrm{k}_{1} \mathrm{y}_{1}\right)-\right. \\
& \left.\left(\mathrm{k}_{7}+\mathrm{k}_{8}+\mathrm{k}_{9}+\mathrm{k}_{10}+\mathrm{k}_{11}\right) \mathrm{y}_{2}\right] \\
& \frac{\mathrm{dy}_{3}}{\mathrm{dx}}=\varnothing\left(\mathrm{t}_{\mathrm{c}}\right) \mathrm{f}\left(\mathrm{C}_{\mathrm{Arh}}\right) \operatorname{cte}\left[\mathrm{v}_{\mathrm{rl}} \mathrm{k}_{2} \mathrm{y}_{1}+\mathrm{v}_{\mathrm{h} 1} \mathrm{k}_{7} \mathrm{y}_{2}-\right. \\
& \left.\left(\mathrm{k}_{12}+\mathrm{k}_{13}+\mathrm{k}_{14}+\mathrm{k}_{15}\right) \mathrm{y}_{3}\right]
\end{aligned}
$$


Am. J. Applied Sci., 7 (1): 71-76, 2010

$$
\begin{aligned}
& \frac{d y_{4}}{d x}=\varnothing\left(t_{c}\right) f\left(C_{A r h}\right) c t e\left[v_{r g} k_{3} y_{1}+v_{h g} k_{8} y_{2}+\right. \\
&\left.v_{1 g} k_{12} y_{3}-\left(k_{16}+k_{17}\right) y_{4}\right] \\
& \frac{d y_{5}}{d x}=\varnothing\left(t_{c}\right) f\left(C_{A r h}\right) c t e\left[v_{r S 1} k_{4} y_{1}+v_{h S 1} k_{9} y_{2}+\right. \\
&\left.v_{1 S 2} k_{13} y_{3}+v_{g S l} k_{16} y_{4}+k_{18} y_{5}\right] \\
& \frac{d y_{6}}{d x}= \varnothing\left(t_{c}\right) f\left(C_{A r h}\right) c t e\left[v_{r S 2} k_{5} y_{1}+v_{h S 2} k_{10} y_{2}+\right. \\
&\left.v_{1 S 2} k_{14} y_{3}+v_{g s 2} k_{17} y_{4}+v_{S 1 S 2} k_{18} y_{5}\right] \\
& \frac{d y_{7}}{d x}= \varnothing\left(t_{c}\right) f\left(C_{A r h}\right) c t e\left[v_{r c} k_{6} y_{1}+v_{h c} k_{11} y_{2}+v_{1 c} k_{15} y_{3}\right]
\end{aligned}
$$

Where:

$\mathrm{X}=$ Represents dimensionless distance of the riser

$\mathrm{y}_{1}=$ The weight fraction of residual oil

$\mathrm{y}_{2}=$ Of heavy fuel oil

$\mathrm{y}_{3}=$ Of light fuel oil

$\mathrm{y}_{4}=$ Of gasoline

$\mathrm{y}_{5}=$ Of liquefied petroleum gas

$\mathrm{y}_{6}=$ Of dry gas

$\mathrm{y}_{7}=$ Of coke

The factors $v_{i j}$ are the ratios of the molecular weight of lump $\mathrm{i}$ over lump $\mathrm{j}$ and are used as stoichiometric coefficients for the reaction of lump $i$ to $\mathrm{j}$, in order to satisfy the global mass balance. The constants of the Eq. 1-7 can be expressed as follows:

$$
\begin{aligned}
f\left(C_{\text {Arh }}\right) & =\frac{1}{\left(1+K_{h} C_{\text {Arh }}\right)} \\
\text { cte } & =\frac{P \overline{M W}}{\text { RTS }_{W h}} \\
S_{W h} & =G_{v} \varepsilon / \rho_{c} L
\end{aligned}
$$

Where:

$\mathrm{C}_{\mathrm{Arh}}=$ Represents $\mathrm{wt} \%$ of aromatic in residual oil

$\mathrm{K}_{\mathrm{h}}=0.128$ represents the heavy aromatic ring adsorption coefficient

$\mathrm{S}_{\mathrm{wh}}=$ Represents true weight hourly space velocity (Mu et al., 2003)

In this scheme, the decay of the catalyst activity due to coke deposition is represented by a function, $\varnothing$ $\left(t_{c}\right)$ which depends on catalyst residence time, $t_{c}$ :

$$
\varnothing\left(t_{c}\right)=\frac{1}{\left(1+\mathrm{Bt}_{\mathrm{c}}^{\gamma}\right)}
$$

where, $\mathrm{B}=162.15, \gamma=0.76$ reported by Jocob and Gross (Jocob and Gross, 1976).

In order to develop a mathematical model for this system the following assumptions are introduced:

- One-dimensional ideal plug flow reactor prevails in the riser without radial and axial dispersion

- The reactor has been considered as an isothermal riser

- Feed viscosity and heat capacities of all components are constant

- The coke deposited on the catalyst does not affect the fluid flow

- The limitation of the model is that lumps proposed are not separated by chemical type with the parameters depending on feedstock and catalyst properties

- Instantaneous vaporization occurred in entrance of riser

- All cracking reactions are considered to take place in the riser

\section{MATERIALS AND METHODS}

The specifications of the commercial riser reactor and operation conditions used in this study and The kinetic parameters for cracking reactions from the literature can be found in Table 1-4, respectively. (Xu et al., 2006).

Table 1: Riser dimensions

\begin{tabular}{lll}
\hline & Length $(\mathrm{m})$ & Diameter $(\mathrm{m})$ \\
\hline Riser reactor & 2.8 & 0.07 \\
\hline
\end{tabular}

Table 2: Average molecular weight

\begin{tabular}{ll}
\hline Species & $\mathrm{Mw}\left(\mathrm{kg} \mathrm{kmol}^{-1}\right)$ \\
\hline Residual lump & 950.0 \\
Heavy lump & 386.0 \\
Light lump & 229.0 \\
Gasoline & 117.8 \\
LPG & 46.7 \\
Dry gas & 18.4 \\
Coke & 400.0
\end{tabular}

Table 3: Operation conditions

\begin{tabular}{ll}
\hline Reaction temperature & $773(\mathrm{k})$ \\
Catalyst to oil ratio & 3.57 \\
Reaction pressure & $150(\mathrm{kPa})$ \\
Catalyst density & $840\left(\mathrm{~kg} \mathrm{~m}^{-3}\right)$ \\
Gas density & $5.3\left(\mathrm{~kg} \mathrm{~m}^{-3}\right)$ \\
Gas velocity & $2.5\left(\mathrm{~m} \mathrm{sec}^{-1}\right)$ \\
\hline
\end{tabular}


Am. J. Applied Sci., 7 (1): 71-76, 2010

Table 4: Kinetic parameters of seven-lumps at $500^{\circ} \mathrm{C}$

\begin{tabular}{lll}
\hline Reaction & $\begin{array}{l}\text { Rate constant } \\
\left(\mathrm{m} 3(\mathrm{~kg} . c a t . h)^{-1}\right)\end{array}$ & $\begin{array}{l}\text { Activation energy } \\
\left(\mathrm{kJ} \mathrm{mol}^{-1}\right)\end{array}$ \\
\hline $\mathrm{RFO} \rightarrow \mathrm{HFO}$ & $\mathrm{K}_{1}: 14.93$ & 50.73 \\
$\mathrm{RFO} \rightarrow \mathrm{LFO}$ & $\mathrm{K}_{2}: 5.78$ & 50.73 \\
$\mathrm{RFO} \rightarrow \mathrm{G}$ & $\mathrm{K}_{3}: 11.69$ & 50.73 \\
$\mathrm{RFO} \rightarrow \mathrm{S}_{1}$ & $\mathrm{~K}_{4}: 3.59$ & 16.15 \\
$\mathrm{RFO} \rightarrow \mathrm{S}_{2}$ & $\mathrm{~K}_{5}: 0.35$ & 16.15 \\
$\mathrm{RFO} \rightarrow \mathrm{C}$ & $\mathrm{K}_{6}: 11.55$ & 16.15 \\
$\mathrm{HFO} \rightarrow \mathrm{LFO}$ & $\mathrm{K}_{7}: 5.78$ & 50.73 \\
$\mathrm{HFO} \rightarrow \mathrm{G}$ & $\mathrm{K}_{8}: 0.94$ & 46.24 \\
$\mathrm{HFO} \rightarrow \mathrm{S}_{1}$ & $\mathrm{~K}_{9}: 0.135$ & 59.75 \\
$\mathrm{HFO} \rightarrow \mathrm{S}_{2}$ & $\mathrm{~K}_{10}: 0.0135$ & 59.75 \\
$\mathrm{HFO} \rightarrow \mathrm{C}$ & $\mathrm{K}_{11}: 0.3272$ & 59.75 \\
$\mathrm{LFO} \rightarrow \mathrm{G}$ & $\mathrm{K}_{12}: 0.5742$ & 46.24 \\
$\mathrm{LFO} \rightarrow \mathrm{S}_{1}$ & $\mathrm{~K}_{13}: 0.0086$ & 59.75 \\
$\mathrm{LFO} \rightarrow \mathrm{S}_{2}$ & $\mathrm{~K}_{14}: 0.0009$ & 59.75 \\
$\mathrm{LFO} \rightarrow \mathrm{C}$ & $\mathrm{K}_{15}: 0.0596$ & 59.75 \\
$\mathrm{G} \rightarrow \mathrm{S}_{1}$ & $\mathrm{~K}_{16}: 0.0003$ & 78.49 \\
$\mathrm{G} \rightarrow \mathrm{S}_{2}$ & $\mathrm{~K}_{17}: 0.0001$ & 78.49 \\
$\mathrm{~S}_{1} \rightarrow \mathrm{S}_{2}$ & $\mathrm{~K}_{18}: 0.0033$ & 59.75 \\
\hline
\end{tabular}

Table 5: Comparison of this study predicted results with industrial plant data

\begin{tabular}{lrrr}
\hline & Plant & Calc. & Deviation (\%) \\
\hline Residual lump (wt\%) & 7.80 & 7.1 & -8.9 \\
Heavy lump (wt\%) & 4.75 & 2.7 & -43.1 \\
Light lump (wt\%) & 19.71 & 16.8 & -14.7 \\
Gasoline (wt\%) & 35.98 & 33.2 & -7.7 \\
LPG (wt\%) & 19.49 & 26.3 & 34.0 \\
Dry gas (wt\%) & 4.14 & 5.3 & 28.0 \\
Coke (wt\%) & 8.13 & 8.6 & 0.7 \\
\hline
\end{tabular}

\section{RESULTS}

In this study, the simulation results are presented and discussed. Table 5 shows the predictions of model are compared with all of exist plant data, According to Table 5 a good agreement between the plant data and the model prediction is observed. Figure 3 shows the concentration profiles along the axial coordinate in the riser. Figure 4 predicts that much of the gas oil conversion occurs in the first $5 \mathrm{~m}$ of the riser, which is correspondence with other FCC unit riser simulation (Ali et al., 1997; Berry et al., 2004; Kimm et al., 1996: Martin et al., 1992; Theologos and Markatos, 1993; Derouin et al., 1997) and commercial data (Xu et al., 2006). There are a number of reasons for this, First, the bottom zone of the riser has a high catalysts concentration, In addition, this catalysts just have been reintroduced from the regenerator, has high activity than it does at higher axial location in the riser, Further more, the concentration of gas oil vapor is highest at the base of the riser in compared to that at higher axial locations, where reaction and molar expansion decrease the gas oil concentration.

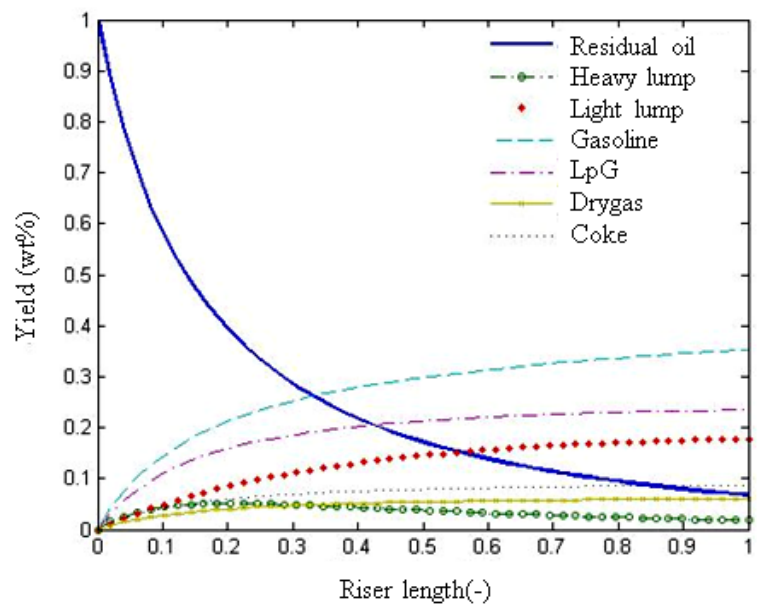

Fig. 3: Steady-state concentration profiles in the riser

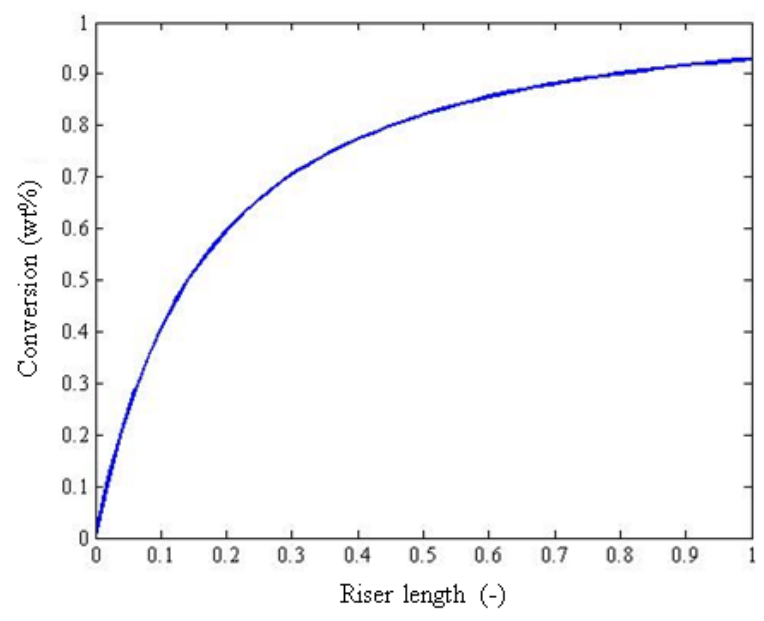

Fig. 4: Conversion (wt $\%)$ versus riser length

Thus the reaction rate of gas oil to products is greatest at the bottom of the riser, contributing to rapid conversion, as mentioned before, most of the cracking reactions occur in the initial section of the riser.

\section{DISCUSSION}

Figure 5 shows the effect of changing inlet temperatures on gasoline yield along the axial coordinate in the riser. According to Fig. 5, because of high conversion in the initial section of riser, with increasing of inlet temperatures, gasoline yield increased, but after the gasoline yield passed through a maximum value, because of coke deposition, decreasing of the gasoline yield is evident. The highest yield was obtained at $1075(\mathrm{k})$, It should be noted that this maximum point is a function of the feed quality, catalyst type and reaction temperature. 


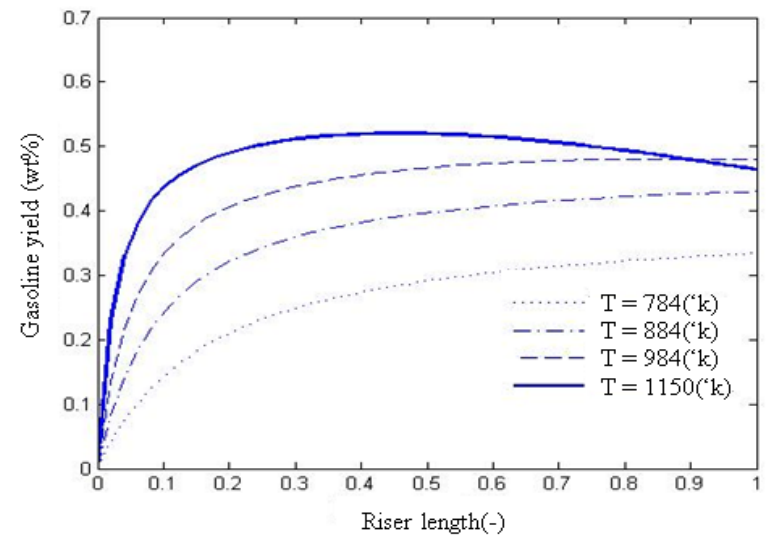

Fig. 5: Effect of changing inlet temperatures on gasoline yield along the axial coordinate in the riser

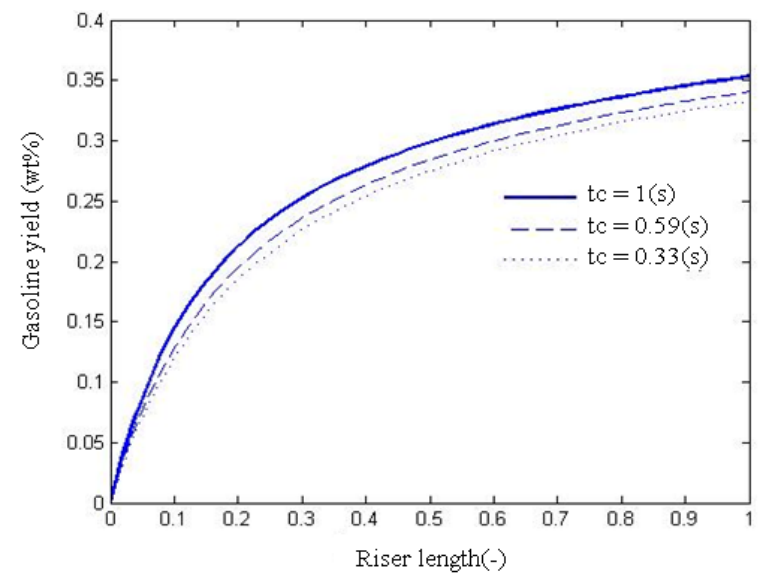

Fig. 6: Effect of changing residence time on gasoline yield along the axial coordinate in the riser

Figure 6 shows that increasing of residence time, the gasoline yield increases, because the short residence time minimizes gasoline cracking and coke yield (Ellis et al., 1998; Kasat and Gupta, 2002; Bollas, 2002). As reaction center of the products and heat carier in the process, catalyst should be paid more attention to, especially the catalyst circulation between reactor and regenerator. A majority of heat required for feedstock vaporization and endothermic reactions in the FCC process comes from burning the deposited coke on spent catalyst surface. The more coke produced in the process, the more steam should be needed for spent catalyst hydrocarbon stripping. Hence precise coke formation prediction is crucial. The separated lump of coke in the model ensures precise prediction of coke.

The advantage of model is the ability to predict LPG, dry gas and coke yields separately which satisfies the users demand and is fit for commercial use. At the point of gas compression, the accurate estimation of lumps by the model gives us guidance to design gas compressor. All the above mentioned conditions demonstrate the significance of lump separation during the model establishment. Component concentration profiles along the riser can be easily described by the model. In this study, the ordinary differential equations Eq. 1-7 must be solved by Runge-Kutta order 4, because the equations are not too stiff, so it has been developed a Matlab code for this purpose. The proposed model is suitable for off-line process simulation as well as online application, which is the basis of process optimization and advanced process control.

\section{CONCLUSION}

A one-dimensional model of the riser section of catalytic cracking unit has been developed by combining a one dimensional predictive riser hydrodynamic model with the seven-lump reaction kinetics model of $\mathrm{Xu}$ et al. (2006). Effect of the operating conditions on the system behavior has also been studied. The model predictions of the gas oil conversion, product yield, were validated by comparison with plant data supplied by Xu et al. (2006). To simulate the FCC riser, the seven-lump model involved residual oil, heavy lump, light lump, liquefied petroleum gas, gasoline, dry gas and coke (to predict the feed conversion and the product distribution) has been developed. The model helps us get good insight into the performance of an industrial riser reactor that would be useful for optimization of Fluid Catalytic Cracking.

\section{REFERENCES}

Ali, H. and S. Rohani, 1997. Dynamic modeling and simulation of riser-type fluid catalyticcracking unit. Chem. Eng. Tech., 20:118-130. DOI: 10.1002/ceat. 270200209

Ali, H., S. Rohani and J.P. Corriou, 1997. Modeling and control of a riser type Fluid Catalytic Cracking (FCC) unit. Trans. Inst. Chem. Eng., 75: 401-412.

Ancheyta-Juarez, J., F. Lopez-Isunza and E. AguilarRodriguez, 1999. 5-Lump kinetic model for gas oil catalytic cracking. Appl. Catal. A, 177: 227-235. DOI: 10.1016/S0926-860X(98)00262-2

Arandes, J.M. and H.I. de Lasa, 1992. Simulation and multiplicity of steady states in fluidized FCCUs. Chem. Eng. Sci., 47: 2535-2540. DOI: 10.1016/0009-2509(92)87089-9

Arbel, A., I.H. Rinard, R. Shinnar and A.V. Sapre, 1995. Dynamic and control of fluidized catalytic crackers. 2. Multiple Steady States and Instabilities. Ind. Eng. Chem. Res., 34: 3014-3026. DOI: $10.1021 / \mathrm{ie} 00048 \mathrm{a} 013$ 
Berry, T.A., T.R. McKeen, T.S. Pugsley and A.K. Dalai, 2004. Two-dimensional reaction engineering model of the riser section of a fluid catalytic cracking unit. Ind. Eng. Chem. Res., 43: 5571-5581.

Bollas, G. M., A.A. Lappasa, D.K. Iatridisa and I.A. Vasalos, 2007. Five-lump kinetic model with selective catalyst deactivation for the prediction of the product selectivity in the fluid catalytic cracking process. Catalysis Today, 127: 31-43. DOI: $10.1016 /$ j.cattod.2007.02.037

Bollas, G., 2002. Modeling small-diameter FCC riser reactors, a hydrodynamic and kinetic approach. Ind. Eng. Chem. Res., 41: 5410-5418.

Corella, J. and E. Frances, 1991. On the Kinetic Equation of Deactivation Cracking Commercial (FCC) Catalysts with Commercial Feedstocks. Stud. Surface Sci. Catal., 68: 375-381. DOI: 10.1016/S0167-2991(08)62657-9

Derouin, C., D. Nevicato, M. Forissier, G. Nild and J. Bernard, 1997. Hydrodynamics of riser units and their impact on fcc operation. Ind. Eng. Chem. Res., 36: 4504-4515. DOI: 10.1021/ie970432r

DOI: $10.1021 / \mathrm{ie} 0202423$

DOI: $10.1021 / \mathrm{ie} 0306877$

Dupain, X., M. Makkee and J.A. Moulijn, 2006. Optimal conditions in fluid catalytic cracking: A mechanistic approach. Applied Catalysis, 297: 198-219. DOI: 10.1016/j.apcata.2005.09.009

Ellis, R.C., X. Li and J.B. Riggs, 1998. Modeling and optimization of a model IV fluidized catalytic cracking unit. AICHE. J., 44: 2068-2079. DOI: 10.1002/aic.690440914

Hagelberg, P. and I. Eilos J. Hiltunen, K. Lipiainen and V.M. Niemi et al., 2002. Kinetics of catalytic cracking with short contact times. Applied Catalyst. A, 223: 73-84. DOI: 10.1016/S0926860X(01)00744-X

Han, I.S. and C.B. Chung, 2001. Dynamic modeling and simulation of a fluidized catalytic cracking process. Chem. Eng. Sci., 55: 1951-1971. DOI: 10.1016/S0009-509(00)00493-0 http://cat.inist.fr/?aModele $=$ afficheN\&cpsidt $=2680$ 749

Jacob, S.M., B. Gross, S.E. Voltz and V.W. Weekman Jr., 1976. A lumping and reaction scheme for catalytic cracking., AICHE. J., 22: 701-713. DOI: 10.1002/aic.690220412

Kasat, R.B. and K. Gupta, 2002. Optimization of industrial FCC units using elitist nondominated sorting genetic algorithm. Ind. Eng. Chem. Res., 27: $1785-1800$. DOI: $10.1016 /$ S00981354(03)00153-4
Kimm, N.K., F. Berruti and T.S. Pugsley, 1996. Modeling the hydrodynamics of down flow gassolids reactors. Chem. Eng. Sci., 51: 2661-2666. DOI: 10.1016/0009-2509(96)00133-9

Kraemer, D., H.I. de Lasa and M. Larocca, 1991. Deactivation of cracking catalyst in short contact time reactors. Ind. Eng. Chem. Res., 69: 355-360. DOI: 10.1002/cjce.5450690143

Lee, L.S., S.W. Yu, C.T. Cheng and W.Y. Pan, 1988. Fluidized-bed catalyst cracking regenerator modelling and analysis., 40: 71-82. DOI: 10.1016/0300-9467(89)80048-6

Lee, L.S., Y.W. Chen, T.N. Huang and W.Y. Pan, 1989. Four-lump kinetic model for fluid catalytic cracking process. Can. J. Chem. Eng., 67: 615-619. DOI: $10.1002 /$ cjce.5450670414

Martin, M.P., C. Derouin and P. Turlier, 1992. Catalytic cracking in riser reactors: Core-annulus and elbow effects. Chem. Eng. Sci., 47: 2319-2324. DOI: 10.1016/0009-2509(92)87054-T

Mu, Z., J. Wang, T. Wang and Y. Jin, 2003. Optimum design of radial flow moving-bed reactors based on a mathematical hydrodynamic model. Chem. Eng. Process., 42: 409-417. DOI: 10.1016/S02552701(02)00065-X

Oliveira, L. and E.C. Biscaia., 1989. Catalytic cracking kinetic models. parameter estimation and model evaluation. Ind. Eng. Chem. Res., 28: 264-271. DOI: 10.1002/aic.690470416

Pugsley, S. and K. Dalai, 2004. Two-dimensional reaction engineering model of the riser section of fluid catalytic crackingunit. Ind. Eng. Chem. Res., 43: 5571-5581. DOI: 10.1021/ie0306877

Theologos, K.N. and N.C. Markatos, 1993. Advanced modeling of fluid catalytic cracking riser-type reactors. AICHE. J., 39: 1007-1017. DOI: 10.1002/aic.690390610

Weekman, V., 1968. A model of catalytic cracking conversion in fixed, moving and fluid-bed reactors. Ind. Eng. Chem. Proc. Des., 7: 90-95. DOI: 10.1021/i260025a018

Xu, O.G., H.Y. Su, S.J. Mu and J. Chu, 2006. 7-lump kinetic model for residual cracking. J. Zhejiang Univ. Sci. A., 7: 1932-1941. DOI: 0.1631/jzus.2006.A1932 